the residue, from which it is inferred that it exists in the form of an alkaline arseniate. The quantity of trisodic arseniate varies from 5.1 to $17.2 \mathrm{mgrms}$ per liter. Bicarbonate of lithium is also present in quantities from 37.9 to 44.3 mgrms per liter.

Onthe Action of Bromine uponDiphenylmethane, C. FRIEDEL and M. BArsonx $(33,337)$. The object of these investigations is to ascertain whethor bromine can be substituted in the place of the bydrogen of the non-aromatic part of the radical. By acting upon one molecule of diphenylmethane with two molecules of bromine under appropriate conditions, bibromo-diphenylmethane may be formed. This when heated with water is decomposed into benzophenone and hydrobromic acid. If one molecule of bromine is used instead of two, monobromodiphenylmethane is formed. The alcoholic solution of the latter acted upon by alcoholic potassa forms mixed ethylbenzohydrolic ether. By treating with amylic alcobol instead of ethylic, and potash, amylbenzohydrolic ether is produced, or if potassic acetate and acetic acid are used we obtain acetate of benzobydrole. Benzohydrolic ether and benzohydrole can also be made from the monobromodiphenylmethane.

On the Constitution of the Salts of Rosaniline and of Analogous Coloring Matters, A. Rosenstient $(33,342)$.

On a Continuous Methorl for the Preparation of Acetic Ether, J. A. Pabst $(33,350)$. - Acetic ether can be made by a process similar to that employed for the manufacture of sulphurse ether. The mixture of alcohol, sulpburic acid and acetic acid which is in the apparatus, gives off at first a little sulphuric ether, but afterwards at $130^{\circ}-135^{\circ}$, acetic ether of $85 \%$. This is washed with a saturated solution of chloride of calcium, dried over chloride of calcium, and redistilled.

\title{
Berichte der Deutschen Chemischen Gesellschaft.
}

Abstractor, H. Exdemann, Ph.D.

Phenyllactic Acids, Eumi ErLandeyer (13, 303).

Phenylbromlactic Acid, Emil ErLenMerer (13,305).

Orthonitrobenzaldehyde and its Behavior towards Nascent Hydrogen, Сн. Rudolph.-Tin and glacial acetic acid produce with orthonitrobenzaldehyde a substance of basic character, $\mathrm{C}_{7} \mathrm{H}_{3} \mathrm{~N}$. The same, with tin and hydrochloric acid, produces $\mathrm{C}_{7} \mathrm{H}_{4} \mathrm{ClN}$. The same reaction was to be employed for other orthonitroaldehydes, the authors intending to first submit the aldehydes of orthonitro- 
phenylacetic and orthophenylglyoxylic acids in the hope of obtaining indol and indigo. The already mentioned publications of Baeyer and Jackson have, however, been the cause that the author has desisted from further work in this direction.

Amides and Anilides of p-oxybutyric Acid, L. Balbiano (I3, 312).

Phenanthrenedisulphonic Acid and some of its Derivatives, Eugen Fischer $(13,314)$. -One part of phenanthrene is gradually added to four parts of pyrosulphuric acid of commerce, and, after a good mixture is obtained, the whole is heated from $\frac{1}{4}$ to $\frac{1}{2}$ hour on the water bath. For the purpose of purification, the lead salt is prepared, and this, decomposed by $\mathrm{H}_{2} \mathrm{~S}$.

The barium salt contains 28.96 per cent. of barium, which corresponds to the formula $\mathrm{C}_{14} \mathrm{H}_{8} \cdot\left(\mathrm{SO}_{3}\right)_{2}$. Ba.

The author has used his material to study a series of reactions: Melting with alkalies, heating with acetyl chloride, potassium cyanide and yellow prussiate of potash, after dehydration, and likewise sodium formate. The investigations are however not sufficiently advanced for publication.

A Series of New Dyestuffs, Euges Fischer (13, 317).Phenanthrene disulphonic acid, when heated with phenols, especially resorcine, produces beautifully colored substances. In this reaction one molecule disulphonic acid and two molecules of resorcine participate; a condensation takes place, water being given off, and a product is formed, possessing a formula analogous to resorcinephthaleine. The analytical results differ, in part, considerably from the calculated composition, and the author therefore assumes that as yet he has not obtained a product free from by-products produced in the reaction.

Phenol disulphonic acid gives with phenols a similar reaction; the product is likewise highly colored.

On Isophthalophenone, E. ADor (I3,320).

On the Action of Carbonic Oxide upon Alkalic Hydrates at Higher Temperutures, A. Z ENTHER.-The author, owing to a publication in thes Journal (13, 23), calls attention to the fact that he has published during the previous summer a treatise upon the action of the substances given in the title, as likewise the action of carbonic oxide upon mixtures of

Sodium methylate and sodium acetate, Sodium ethylate and sodium acetate, Sodium ethylate and sodium valerate, Sodium anylate and sodium valerate. 
These were printed in Jena's Zeitschrift fuer Naturwissenschaft, Supplement to Vol. XIII.

Since then, the author has examined the action of carbonic oxide upon mixtures of

Sodium amylate and sodium acetate,

Sodium phenylate and sodium acetate,

Sodium phenylate and sodium carbonate,

Sodium ethylate and sodium carbonate,

Sodium ethylate and sodium benzoate,

Sodium ethylate and sodium phenylacetate,

Sodium phenylate and potassium oxalate,

Sodium ethylate and potassium oxalate,

Sodium ethylate and sodium succinate,

and also the action of carbonic oxide upon sodium ethylate and sodium cinnamate. The investigation will be continued, and will embrace the action upon polybasic alcohols.

The Synthetic Preparation of Formic Acid, O. LoEw (I3, 324).--The author, owing to a publication in this JourNaL $(I 3,23)$, calls attention to a reaction published by him in 1864 . Carbou bisulphide and water, with iron filings in excess, heated to $100^{\circ}$ for some time in a sealed tube, produced iron sulphide, iron formate, carbon dioxide and also two more substances of more complicated composition.

Identiflcation and Determination of Chlorine in the Presence of Bromine and lodine, G. VoRTMANN.-Bromine and iodine may be driven off by boiling a solution of the salts to be tested for chlorine, with lead peroxide and acetic acid. They pass off mainly as bromine and iodine; a small portion, however, is converted into bromic and iodic acids, which remain with the lead peroxide added in excess. After filtration the solution may be tested for chlorine. The reaction is reliable enough for quantitative determinations.

Cinnamic Aldehyde obtained by the Pancreatic Digestion of Fibrine, J. Ossikovszky (I 3, 326).

On the Constitution of Tyrosine and Skatole, J. Ossikovszky (I3, 328).

On the Velocity of Reactions, B. PAwLEwSKI.-The author finds that using the same acid with barium, strontium and calcium carbonate, the velocity of the reaction is in inverse proportion to the atomic weight of the metal contained in the carbonate.

Vanilline in certain Unrefined Beet Sugars, C. SCHEIBLER $(\mathbf{I}, 335)$. 
Some Dichromates, K. Preis and B. Raymax (I3, 340).-The author describes in this paper the barium, strontium and lead dichromates.

On the Action of Iolline upon Aromatic Compounds with long Side Chains, B. RAYMAN and K. PREIS (I3, 344).-Iodine, acting upon cymole, produces a series of hydrocarbons which commence to boil below $100^{\circ}$, the boiling pt. gradually rising to $300^{\circ}$. The hydrocarbons produced are the same as those produced by the action of iodine upon oil of turpentine. The hypothesis that oil of turpentine produces under the influence of iodine first cymole, seems therefore in part at least verified.

Iodine acting upon camphor produces the same hydrocarbons.

On the Oxidation of Sulphaminemetatoluic Acid, IRA REMSEN $(13,347)$.-Treats of the reliability of Lassaigne's reaction for nitrogen, which consists in the melting of the substance to be tested with sodium, and testing a solution obtained from the melt, with iron salts, which in the presence of nitrogen will produce a blue precipitate. The anthor defends Lassaigne's nethod against the objections raised by Jacobsen.

On the Splitting up of Inactive Malic Acid, G. J. W. BREMER $(13,351)$. -The separation of the two acids, which act upon polarized light, from the inactive acid obtained by the action of HI upon racemic acid, was attained by the preparation of the cinchonine salts. The cinchonine salt of the acid, which turns the plane of polarization to the left, is precipitated, while the other salt remains in solution.

Dinitronnphthalene, F. Beilsteis and A. Kurbatow (I3, 353).- $\alpha$-dinitronaphthalene, heated with nitric acid, 1.15 specific gravity, to $150^{\circ} \mathrm{C}$. in a sealed tube, gave nitrophthalic acid, dinitrobenzoic acid and some picric acid; while the $\beta$-compound gave dinitrophthalic acid, dinitrobenzoic acid and some picric acid. A description of dinitrophthalic acid follows.

On Dinitrobenzoic Acid, F. Beilstein and A. Kurbatow (I3, 355).-The dinitrobenzoic acid obtained in the reactions of the preceding paper is, as determined by the properties of its ethyl ether, the well-know.n modification.

Action of Dehydrating Substances upon Acids, B. $\mathrm{V}_{\mathrm{ANGEL}}$ (13,355).

On the Condensation of Benzohydrole and Naphthalene, A. LEHNE (I3, 358). 
On Cubic Alum and the Accommodation of Chrome Alums, A. Poris (I3, 360). - In order to produce cubic crystals of alum, which remain clear, the author adds soda to the alum solution instead of, as has formerly been done, potash or ammonia; chrome alum could only then be obtained in cubes, when an alumina alum cube, prepared by the first described method, was allowed to glow in a chrome alum solution. A series of other crystallizations, made under varying conditions, follows.

On Gluten, Th. Weyl and Biscuoff (13,367).--Accolding to the authors, gluten is not originally contained in the flour, but is produced from a substance called vegetable myosine by the action of a ferment. The investigation will be continued.

Contributions to the Knowledge of Daturine, ERNST Schumd (13, 370).-The author maintains the identity of daturine and atropine, by a direct comparison of the daturines and atropines from different manufacturers, and prepared by himself from the plants.

Artificial formation of Tropaic Acial, A. ILADENBURG and I. RüGhzimer (I3, 373).-Hydrotropaic acid on oxidation by means of potassium permanganate, yielded the atrolactinic acid of Fittig and Wurster. The latter acid was converted into atropaic acid on distillation with dilute hydrochloric: acid. Tropaic acid was obtained by reduction of the chloroatropaic acid produced by the addition of hypochlorous acid to the above atropaic acid. The authors assign to atrolactinic acid and tropaic acid the following formula :

$\mathrm{C}_{6} \mathrm{H}_{5} \mathrm{C} \cdot \mathrm{CH}_{3} . \mathrm{OH} . \mathrm{COOH}=$ atrolactinic acid.

$\mathrm{C}_{6} \mathrm{H}_{5} \mathrm{CH} . \mathrm{CH}_{2} \mathrm{OH} . \mathrm{COOH}=$ tropaic acid.

Upon Daturine, A. LADExburg and G. Meyer (I3, 380).--The authors conctude that daturine, hyoseyamine and duboisine are identical.

Aromntic Amide Acids, Ferd. Tremans (I3, 381).-Benzaldehydecyanhydrine, on digestion with alcoholic ammonia at $60-80^{\circ}$, in sealed vessels, yields benzamidocyanide, which on decomposition by means of dilute hydrochloric acid, yiclds phenylamadoacetic acid. This acid is identical with the phenylamidoacetic acid of Stocckenius (Berl. $B e r .$, I I, 2002) obtained in the reaction of phenylbromoacetic acid and ammonia.

Diphenyl Derivatives, containing Sulphur, S. GABRIEL and A. Deursch (13,386).-Derivatives of diphenylmonosulphonic acid. 
Some Experiments upon the Vapor Densities of the Alkali Metuls, Victor Meyer (I3, 391).-The vapor density of sodium cannot be determined in glass, porcelain, silver or platinum vessels, as the vapor or the metal acts upon these materials. The author expects to repeat his experiments in vessels made of graphite.

Behuvior of Iodine at High Temperatures, ViCTOR MEYER (I3, 394).-The experiments were performed both in glass, porcelain, and in platinum vessels. The following results were obtained: The density of iodine at $600^{\circ}$ corresponds to the formula $I_{2}$; at $800^{\circ}$ a marked decrease becomes observable. The density is constant between $1027-1567^{\circ}$, corresponding exactly to the value calculated for $\frac{2}{3} I_{2}$.

Contribution to the Knowledge of Chlorine, V. MEYER and H. Z ÜBLIN (13,339). - The authors find the vapor density of free chlorine gas to correspond to the value calculated for $\mathrm{Cl}_{2}$, while nascent chlorine, according to previous experiments, corresponds to $\frac{2}{3} \mathrm{Cl}_{2}$ (Berl. Ber., 12, 1430).

Some Observations on Vapor Densities, V. MEYER (I3, 401).

Platinic Bromide, V. MEYER and H. ZÜBLIN (I3, 404).

Density of Bromine Vapor at Yellow Heat, V. MEYER and H. $Z_{\text {ÜBLIN }}$ (I3, 405). - The vapor density of nascent bromine from platinic bromide was found to correspond to $\frac{2}{3} \mathrm{Br}_{2}$.

Calorimetric Determination of Temperature, V. MEYER (I3, 407).

Potassium Indigo-vhite-sulphate and Indoxylsulphate, E. Batjrasx and Fern. Tiemans (I3, 408). - The authors give a series of reactions which prove that the two substances, mentioned in the title, differ sufficiently to justify the position which the authors have taken against Baeyer, who doubts the existence of potassium indoxylsulphate.

Fittica's Fourth Nitrophenole, S. Natanson (13, 415). - The author has been unable to obtain this substance by following Fittica's method, and concludes that this substance, the existence of which would not be possible according to Kekulé's theory, does actually not exist. Fittica stated that it was fluid at ordinary temperature; boiling point, $190^{\circ}$.

Contribution to the Constitution of Phthalylchloride, E. von Gerichten (I3, 41 $\tau$ ).-Not suitable for abstraction. 